\title{
Evaluating the toxicity of oil of lemon eucalyptus, Corymbia citriodora (Hook.), against larvae of the Asian tiger mosquito and non-target fish and larval amphibians
}

\author{
Santi Escartin ${ }^{1} \&$ Simone Mariani ${ }^{1,2}$ \\ 1 Associació Mediambiental Xatrac. C/ Font d'en Bandina 3, Urb.Font de Sant Llorenç. Bústia 39. 17.310 Lloret de Mar. Spain. \\ 2 Departament d'Ecologia, Facultat de Biologia, Universitat de Barcelona. Diagonal 643, 08028 Barcelona, Spain.
}

Existe una corrección de este trabajo (vol.37)/ There is a corrigendum note of this article (vol.37).

\begin{abstract}
Resumen
Correspondence

S. Mariani

E-mail: smariani@ub.edu

Received: 30 June 2014

Accepted: 27 October 2014

Published on-line: 30 October 2014

Evaluación de la toxicidad del aceite del eucalipto limón, Corymbia citriodora (Hook.), contra las larvas de mosquito tigre y peces y anfibios no objetivo

Hemos probado la toxicidad del aceite del eucalipto limón (OLE) contra las larvas de mosquito tigre Aedes (Stegomya) albopictus (Skuse, 1895) (Diptera: Culicidae) y contra vertebrados acuáticos no objetivo, el pez Gambusia affinis (Baird and Girard, 1853) y el renacuajo de la rana Pelophylax perezi (López-Seodane, 1885). La mezcla acuosa de OLE fue efectiva como larvicida y letal para gambúsias y renacuajos. La mezcla acuosa expuesta durante una semana al aire libre no tuvo efectos sobre las larvas. EI OLE puro aplicado sobre la superficie del agua matólas larvas a muy bajas concentraciones y sin tener en cuenta el volumen del agua. EI OLE ha mostrado ser un compuesto útil contra las larvas de mosquito tigre especialmente en los lugares de cría aislados de los ecosistemas nativos.
\end{abstract}

Palabras clave: Terpenoide, Larvicida, Ecotoxicidad, Aedes (Stegomyia) albopictus, Diptera, Culicidae.

\begin{abstract}
We evaluated the toxicity of oil of lemon eucalyptus (OLE) against larvae of the tiger mosquito Aedes (Stegomya) albopictus (Skuse, 1895) (Diptera: Culicidae) and non-target aquatic vertebrates, the fish Gambusia affinis (Baird and Girard, 1853) and the tapole of the frog Pelophylax perezi (López-Seodane, 1885). The water-mixture of OLE was effective as a larvicide and lethal to both mosquitofish and tadpoles in the short-term. The water-mixture left in the open air over a week had no effect on larvae. Pure OLE released on the water surface killed larvae at very low concentrations irrespectively of the volume of water medium. OLE seems a useful compound to be used against tiger mosquito larvae especially in mosquito breeding sites isolated from native ecosystems.
\end{abstract}

Key words: Terpenoid, Larvicide, Ecotoxicity, Aedes (Stegomyia) albopictus, Diptera, Culicidae. 


\section{Introduction}

Since a single female mosquito may produce more than one hundred eggs per blood meal (Hawley 1988), the use of larvicides to treat breeding sites may appear an effective control method against these pests. There is growing interest in controlling mosquitoes and other pests using chemical compounds with the least possible threat to the environment. Active compounds extracted from a variety of plant species are well-known for their properties as insecticides (Monzon et al. 1994, Chantraine et al. 1998, Lucia et al. 2008). Largely based on their botanical extraction, these products are often labelled as "natural", "eco-friendly" or "environment-friendly". Nonetheless, most research merely takes for granted that plant essential oils biodegrade more easily, bioaccumulate less and are therefore less harmful than synthetic compounds, both to the environment and humans (Isman 2000, Dharmagadda et al. 2005, Singh et al. 2005, 2007).

Among the major types of botanical products used as insecticides, plant essential oils are known to contain terpenoids and derivates with neurotoxic activity, which can be lethal to insects (see Isman 2006).

These terpenoids are produced as direct and indirect plant defence mechanisms, by far representing the most frequent compounds found among their metabolites (see Mithöfer \& Boland 2012). The mechanisms by which terpenoids may act as insecticides are summarised in Mithöfer \& Boland 2012.

One such compound, PMD (p-Menthane-3,8diol), is well known for its efficient mosquito repellent properties (see Barasa et al. 2002, Carroll and Loye 2006). This has led to increasing industrial interest in the production of this terpenoid and the compound has been registered by the USA Environmental Protection Agency (EPA) and the European Biocidal Products Directive (BPD). PMD dominates the water-soluble fraction of the extract of the lemon eucalyptus Corymbia citriodora (Hook.), a commonly available natural repellent. It can also be obtained from a number of chemical precursors, among them, through acid conversion of the monoterpenoid Citronellal at high temperatures (Mpuhlu 2007). A variable amount of Citronellal (often more than $50 \%$ of the essential oil) can be extracted by distillation of both leaves and branches of the lemon eucalyptus, among other plants (see Carroll \& Loye 2006, for details).

The essential oil of lemon eucalyptus is better known as OLE in the USA and as Citriodiol, both in the USA and Europe. The oil is also well known for its larvicidal properties (Singh et al. 2007, Idris et al. 2008, Zhu et al. 2008), although it is still unclear if PMD, Citronellal or other components either in the oil or the water-soluble fractions of the extract is primarily responsible for this larvicidal property (see Zhu et al. 2008). For the sake of simplicity, and in the absence of a separate evaluation of the activity of each of its components elements, we henceforth refer to the essential oil of the lemon eucalyptus C. citriodora as OLE.

Many insect larvae, notably mosquito larvae of the genus Aedes Meigen, 1818, inhabit tiny water bodies such as water-logged tree holes (Yates 1979), but they can also colonise a host of artificial, manmade objects that retain standing water, from road drains (see Hribar et al. 2004) to used tires (Reiter 1998). While the use of botanical insecticides has burgeoned in recent decades as an agent of mosquito control, it is critical that their larger ecotoxiciy be assessed before their widespread application. In fact, botanical-based larvicides may be very effective control agents, although their broad-based mechanism of action may have flow-on consequences for a host of nontarget species if they find their way into natural water bodies.

The present study aimed to address two main gaps in our knowledge on the OLE properties both as a mosquito larvicide and as a possible threat to non-target species. First, whereas the toxicity of OLE against the larvae of several mosquito species has been tested by other researchers at comparable concentrations of such compounds (e.g. Singh et al. 2007), its potential effect on aquatic vertebrates has not been clearly evaluated (but see Zhu et al. 2008). Second, there are no bioassays measuring the medium-term persistence (e.g. 1-week) of OLE larvicidal properties. Both effects on vertebrates and persistence in the environment are too often overlooked in bioassays, especially when botanical-based compound are tested.

Different OLE concentrations (between 3.9 and $\sim 1700 \mathrm{ppm}$ ) have been shown to have high to 
none effects on the mortality of mosquito larvae (Chantraine et al. 1998, Amer \& Melhorn 2006, Idris et al. 2008) and the effectiveness of OLE crude extracts (i.e. Citronellal and Eucaliptol) as surface films has been once assessed by Corbet et al. (2000) against Culex (Culex) pipiens form molestus Forskål, 1775. Hence, our main goals were to evaluate the toxicity of OLE against tiger mosquito larvae and non-target vertebrates. To accomplish with our first purpose, we tested: a) medium to high concentrations (relatively to other studies, see above) of OLE available in the Spanish market against early larval instars of the tiger mosquito Aedes (Stegomyia) albopictus (Skuse, 1895), b) the persistence of possible larvicidal properties of dissolved OLE in the aquatic environment, c) the effectiveness as larvicide of small amounts of pure OLE, applied directly to the surface of larval-infested water bodies, irrespective of the volume beneath them. The second purpose aimed at testing the effects of medium concentrations of OLE with non-target aquatic vertebrates, the exotic fish Gambusia affinis (Baird and Girard, 1853) and the tadpole of the endemic frog Pelophylax perezi (López-Seodane, 1885) inhabiting both urban and wild habitats.

\section{Materials and methods}

\section{Test animals}

The Asian tiger mosquito Ae. albopictus was used for these bioassays. The propensity of this species to lay eggs in a variety of containers has allowed it to colonize most urban and semi-urban areas (Hawley 1988). Furthermore, thanks to the extraordinary ability of Ae. albopictus to be passively dispersed (Lounibos 2002) and colonize a variety of different habitats, it has become widespread across the world being present in most continents today (Paupy et al. 2009). It is a recent colonizer of increasing concern in southern Europe, affecting both the quality of life and general health of human populations in Catalonia (Spain) (Abramides et al. 2011). While for the nuisance its bite itself can be a considerable problem for public health (Eritja et al. 2005), the main concern about the spread of Ae. albopictus is that it is a vector for several arboviruses (Paupy et al. 2009). As with most human-biting mosquitoes, control programmes have focused on identifying larval sites and treating them with larvicidal compounds.
For our study, we used Ae. albopictus larvae (3rd and 4th instars) from ovitraps filled with rain water and established in a backyard garden in Lloret de Mar (Catalonia, Spain). The larvae were held in a 7-L container filled with the same ovitrap water medium for four days before the bioassays started.

Gambusia or western mosquitofish (G. affinis, is a native species of the American continent and is now widespread in Europe. Adult specimens of both sexes (about $5 \mathrm{~cm}$ length) collected from a nearby pond were chosen to assess the toxicity of OLE against a non-autochthonous, non-target fish species.

Tadpoles (2nd and 3rd instars) of the Iberian water frog $(P$. perezi) were collected from a nearby temporary puddle, using a small fish net and placed to carry in a 10-L tank filled with tap water. The frog is an endemic and common species of the Iberian Peninsula and Southern France. This species was chosen to assess toxicity of OLE against autochthonous, non-target amphibians.

Before they were used for testing, mosquitofish and tadpoles were held in 40-L aquaria filled with filtered rain water for 10 days under natural light-dark and temperature conditions. The animals were fed on TetraMin ${ }^{\circledR}$ flakes every $24 \mathrm{~h}$. None of the animals in the aquaria died before the bioassays started.

\section{Bioassays with mosquito larvae}

We conducted separate experiments to achieve the proposed objectives. The OLE used for all experimental treatments was the crude extract of leaves and roots of the eucalyptus species $C$. citriodora. The product, as well as its chromatographic analysis, was provided by DICANA SL. It showed the presence of 12 main chemical compounds, Citronellal and Citronellol the most abundant among them (Table1).

To test the effect of diluted concentrations of OLE (specific weight $=0.869 \mathrm{gmL}^{-1}$ ) on mosquito larvae, we mixed three different volumes of OLE $(0.25,0.5$, and $1.25 \mathrm{~mL})$ with $5 \mathrm{~mL}$ of a distilled water solution of polysorbate (Tween 80 ). These emulsions were then added to $500 \mathrm{~mL}$ of filtered rain water (using $2.5 \mu \mathrm{m}$ cellulose filters) and gently shaken until a limpid heterogeneous mixture was obtained. As a result, three different stock solutions were prepared, 434.5, 869 and 
$2150 \mathrm{ppm}$, by adding respectively $5.25,5.5$, and $6.25 \mathrm{~mL}$ of the OLE - polysorbate solution to the water.

All the experiments were conducted in the open on a terrace from our facilities in Lloret de Mar. Three replicate samples of five mosquito larvae of the same size were introduced into glass jars $(125 \mathrm{~mL})$ filled with $75 \mathrm{~mL}$ of each water-mixture (434.5 ppm, $869 \mathrm{ppm}$, and $2150 \mathrm{ppm}$ ) plus three control replicates of the $5-\mathrm{mL}$ emulsifier (distilled water and Tween 80) without OLE. Sixty larvae were used altogether, 45 in the treatments and 15 in the controls. The containers were interspersed over a table and left under a natural light-dark regime but protected from direct sun. We checked for mosquito larval mortality at $\sim 30$ min intervals. A mosquito larva was considered dead when no movement was observable after probing it with a plastic pipette. We ended the trial after $15 \mathrm{~h}$, when there were no further changes in larval mortality between repeated observations. Large differences in percent mortality have been reported in the literature for similar concentrations of the same compounds (see Introduction). Hence, rather than carrying out a unique experiment with more samples we preferred to repeat the trial a day later using fresh mixtures in an identical setting. Since further changes in larval mortality dis-

\begin{tabular}{|cc|}
\hline Compound & $\%$ \\
\hline alpha-Pinene & 0.46 \\
\hline beta-Pinene & 1.37 \\
\hline Myrcene & 0.22 \\
\hline Eucaliptol & 2.28 \\
\hline gamma-Terpinene & 0.2 \\
\hline Linalol & 0.59 \\
\hline Isopulegol & 8.08 \\
\hline Citronellal & 59.36 \\
\hline Alpha-Terpineol & 0.12 \\
\hline Citronellol & 14.66 \\
\hline Citronellyl Acetate & 4.46 \\
\hline Beta-Cariofillene & 1.23 \\
\hline
\end{tabular}

Tabla 1: Los principales compuestos químicos presentes en el aceite de Corymbia citriodora utilizado. (Datos proporcionados por DICANA S.L.).

Table 1: Main chemical compounds in the essential oil of Corymbia citriodora used. (Data provided by DICANA S.L.) appeared earlier in this trial, the experiment ended after $10.5 \mathrm{~h}$.

To assess the medium-term persistence of OLE in the medium, glass jars with the same OLE concentrations as in the previous experiments with the mosquito larvae were left for one week in the open air. This experiment had the same number of treatments and replicates as the previous one. Five mosquito larvae were then added to each of the jars and their mortality recorded as described above. Organisms, leaves, or other material, which accidentally fell into the containers, were carefully removed with tweezers from the jars. This experiment lasted $24 \mathrm{~h}$.

To assess the effectiveness of OLE introduced on the surface of a water body (with no emulsion) a constant volume $(0.1 \mathrm{~mL})$ of the same oil used in the previous experiments was gently added to identical plastic containers $\left(\sim 50 \mathrm{~cm}^{2}\right.$ surface area) with different filtered rain water volumes, 100, 200, and $400 \mathrm{~mL}$. Three replicates of each OLE volume and three replicate controls with the filtered rain water were set up under the same conditions as for the experiments above. Five mosquito larvae were first added to each of the containers (60 larvae altogether). In each of the treatments (9 replicates altogether), a thin surface layer of undiluted oil was carefully added to the container (without stirring). Mosquito larval mortality was checked after 90, 210, and $1200 \mathrm{~min}$.

\section{Bioassays with non-target animals}

Mortality for both mosquitofish and frog tadpoles was tested using only the minimum concentration of OLE previously used in the experiments with the mosquito larvae (434.5 ppm). Hence, three replicates for the OLE treatment and three replicates for the control treatment were set up using PET, 1.5L water bottle bottoms with $170 \mathrm{~mL}$ total volume of either of OLE water-mixtures (treatments) or the emulsifier without OLE (controls) and left under the same conditions as in the experiments with the mosquito larvae described above. Three healthy mosquitofish or tadpoles of the same sizes were added to each container and tracked for mortality (18 tadpoles plus 18 fish altogether). Because of the very rapid response observed, these experiments lasted 10 and $35 \mathrm{~min}$ for the mosquitofish and the tadpoles respectively. Mortality in the controls was checked at $90 \mathrm{mi}-$ nutes after the start of both the experiments. 


\section{Statistical analysis}

There are plenty of estimations of OLE LC 50 against mosquito larvae in the literature. For this reason, our experimental design was not addressed at determining the median lethal concentration. Rather we aimed at testing the effectiveness of medium to high concentrations of OLE under a univariate design with treatments (OLE concentrations and controls) as the only factor. Data from our experiments showed a very poor dispersion of the mean and unequal variances among the replicates in both treatments and controls. Overall, most control samples showed total survival whilst most organisms died in the OLE treatments at the end of the experiments. While statistical analysis can be circumvented in these cases, we proceeded to compare the data from the experiments by a Kruskal-Wallis non-parametric one-way analysis of variance. Mann-Whitney U comparisons were used to show differences among paired observations.

Because of the abrupt and massive mortality recorded in the OLE treatments and full survival in the control treatments, no statistical analysis was performed with the data from the experiment with fish and tadpoles.

\section{Results}

\section{Mosquito larvae}

Mortality in the first trial of the first experiment with the mosquito larvae was recorded only for the maximum concentration treatment $(2150 \mathrm{ppm})$ after 60 min (Fig. 1). In both the highest and the medium concentration treatments total mortality was recorded after $260 \mathrm{~min}(4.5 \mathrm{~h})$. At the end of the experiment $(15 \mathrm{~h})$ more than $50 \%$ of the larvae of the lower concentration treatment $(434.5 \mathrm{ppm})$ died (Fig. 1). No more larvae died after $15 \mathrm{~h}$ and no mortality was recorded in the control treatments. There were significant differences between treatments at the end of the first trial (Table 2). Post-hoc comparisons showed that both the highest and the medium OLE concentrations were significantly different from the lowest concentration and the control (Table 2).

During the second trial larval mortality was sooner noticeable than in the first trial. After 30 min, in fact, mortality was recorded in all the OLE treatments (Fig. 2). The highest concentration

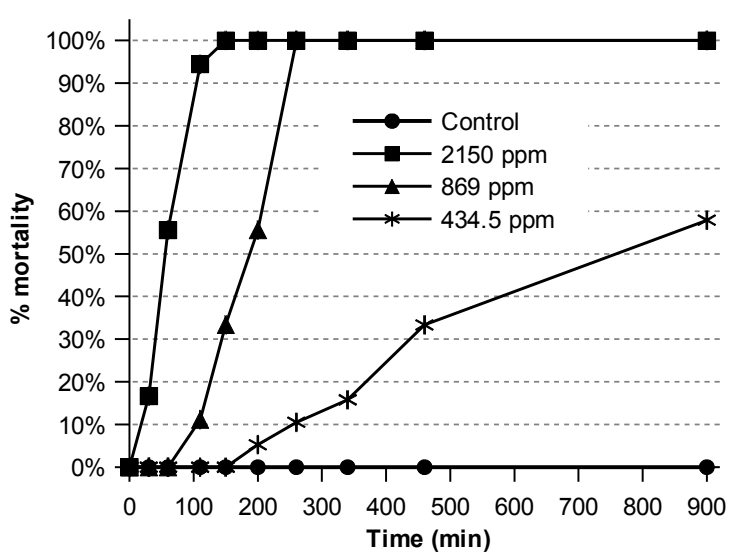

Figura 1: Evolución en el tiempo de la mortalidad en porcentaje para el primer ensayo con las larvas de mosquito y la mezcla acuosa de OLE. Se muestran los promedios y los errores estándar. Figure 1: Evolution of the percent mortality through time for the first trial of the experiment with the mosquito larvae and the water-mixture of OLE. Means and standard errors are shown.

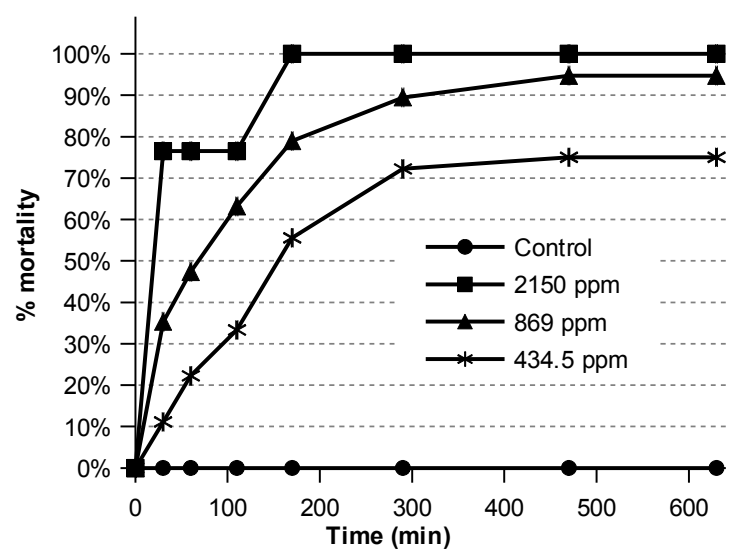

Figura 2: Evolución en el tiempo de la mortalidad en porcentaje para el segundo ensayo con las larvas de mosquito y la mezcla acuosa de OLE. Se muestran los promedios y los errores estándar.

Figure 2: Evolution of the percent mortality through time for the second trial of the experiment with the mosquito larvae and the water-mixture of OLE. Means and standard errors are shown.

Asian tiger mosquito larvae and mixed OLE

\begin{tabular}{|c|c|c|c|c|}
\hline $1^{\text {st }}$ trial & $\begin{array}{c}\text { Chi } \\
\text { Square }\end{array}$ & DF & $p$ & $\begin{array}{l}\text { Pairwise comparisons, } \\
\text { Mann-Whitney } \mathrm{U} \\
\text { (container volumes } \mathrm{mL} \text { ) }\end{array}$ \\
\hline $15 \mathrm{~h}$ & 10.8219 & 3 & 0.0127 & $2150=869>434.5=\mathrm{CONTROL}$ \\
\hline $2^{\text {nd }}$ trial & $\begin{array}{c}\text { Chi } \\
\text { Square }\end{array}$ & DF & $p$ & $\begin{array}{l}\text { Pairwise comparisons, } \\
\text { Mann-Whitney U } \\
\text { (container volumes } \mathrm{mL} \text { ) }\end{array}$ \\
\hline $10.5 \mathrm{~h}$ & 10.8659 & 3 & 0.0125 & $2150=869>434.5=$ CONTROL \\
\hline
\end{tabular}

Tabla 2: Resultados del análisis de la variancia Kruskal-Wallis de un factor (tratamiento) relativos al experimento con las larvas de mosquito y la mezcla acuosa de OLE. Se enseñan los resultados de las comparaciones múltiples.

Table 2: Results of the Kruskal-Wallis one-factor (treatment) analysis of variance relative to the experiment with the mosquito larvae and the water-mixture of OLE. The results of the multiple comparisons are shown. 
treatments had significantly higher mortality than the lowest concentration and the control treatments (Table 2), although the medium concentration treatment never achieved total mortality. No more larvae died after $10.5 \mathrm{~h}$.

Mosquito mortality was rather homogenous among the treatments in the experiment with the floating OLE and differences between the treatments and the controls were easily observable at all times (Fig. 3). Twenty $h$ of the start of the experiment, $100 \%$ of the larvae in the treatment samples with OLE floating on the water died while $93.3 \%$ survived in the control treatments. There were significant differences in the mortality between the treatments and the controls (Table 3).

No mortality of mosquito larvae was recorded after $24 \mathrm{~h}$ in any of the 12 glass jars left for one week in the open.

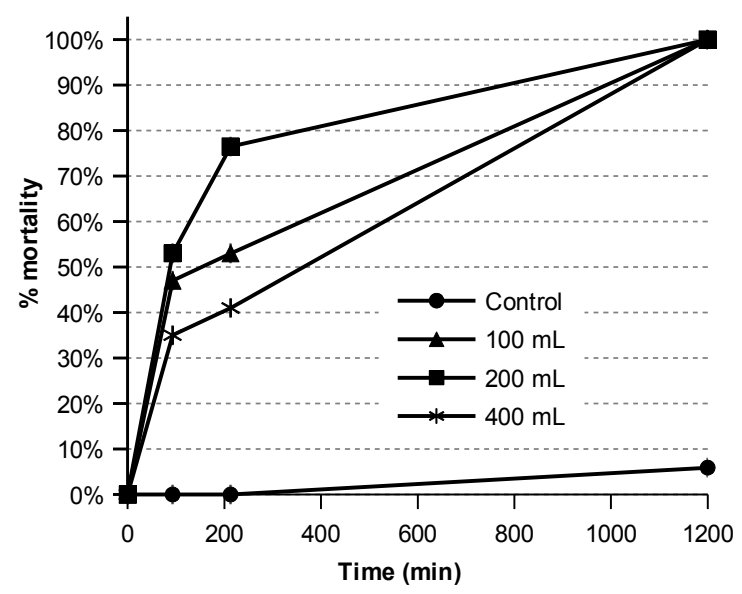

Figura 3: Evolución en el tiempo de la mortalidad en porcentaje para el experimento con las larvas de mosquito y el OLE aplicado directamente sobre la superficie del agua. Se muestran los promedios y los errores estándar.

Figure 3: Evolution of the percent mortality through time for the experiment with the mosquito larvae and the OLE applied directly on the water surface. Means and standard errors are shown.

Asian tiger mosquito larvae and floating OLE

\begin{tabular}{|c|c|c|c|c|}
\hline & $\begin{array}{c}\text { Chi } \\
\text { Square }\end{array}$ & DF & $p$ & $\begin{array}{l}\text { Pairwise comparisons, } \\
\text { Mann-Whitney } \mathrm{U} \\
\text { (container volumes } \mathrm{mL} \text { ) }\end{array}$ \\
\hline $20 \mathrm{~h}$ & 10.8 & 3 & 0.0129 & $100=200=400>$ CONTROL \\
\hline
\end{tabular}

Tabla 3: Resultados del análisis de la variancia Kruskal-Wallis de un factor (tratamiento) relativos al experimento con las larvas de mosquito y $0,1 \mathrm{~mL}$ de OLE aplicado sobre la superficie de diferentes volúmenes de agua (100, 200 y $400 \mathrm{~mL})$. Se enseñan los resultados de las comparaciones múltiples.

Table 3: Results of the Kruskal-Wallis one-factor (treatment) analysis of variance relative to the experiment with the mosquito larvae and $0.1 \mathrm{~mL}$ of OLE applied to the surface of different water volumes $(100,200$, and $400 \mathrm{~mL})$. The results of the multiple comparisons are shown.

\section{Non-target species}

All the mosquitofish died in the OLE treatments after just $10 \mathrm{~min}$. Similarly, all the frog tadpoles died within $35 \mathrm{~min}$ of the start of the experiment. No mortality was recorded in any of the control treatments for the non-target species even after 90 minutes.

\section{Discussion}

The effectiveness of the oil extract by the lemon eucalyptus $C$. citriodora as a mosquito repellent has long been recognized (summarized in Carroll \& Loye 2006) and there is a clear global commercial interest for PMD, both natural and synthetic (Barnard \& Xue 2004). In Catalonia (Spain), for instance, where the presence of the tiger mosquito represents a relatively recent issue (the first recording dating back to 2004 (Aranda et al. 2006)), PMD and Citriodiol are already being proposed as mosquito repellents in a city hall's web page.

The larvicidal properties of any derivate of OLE essentially depend on the amount used, the lower the concentration the higher the differences found among different trials. Our results support that the maximum larvicidal activity of water-mixed OLE can be easily achieved in less than $10 \mathrm{~h}$, at concentrations between 500 and 1000 $\mathrm{mgL}^{-1}$. Some of the differences found in the literature (see Amer \& Mehlhorn 2006, Singh et al. 2007, Idris et al. 2008) might be explained by the fact that, among the OLE components, Citronellal has been shown to have very weak larvicidal properties against $A e$. albopictus larvae whilst both Citronellol alone and the whole OLE are very efficient in killing larvae (Zhu et al. 2008).

Synthetic compounds such as the N,N-Diethylmeta-toluamide (DEET), which is known for both its property as mosquito repellent and larvicide (see Xue et al. 2001), evidently represent a much more severe environmental threat than organic compounds (e.g. OLE). They are known to persist in wastewater treatments (Pereira \& Hostettler 1993, Kolpin et al. 2002) and show general lack of environmental biodegradation (but see RiveraCancel et al. 2007). While no analysis of the water medium was performed to detect whether any OLE compound was still present in our treatments after one week, its toxicity against mosquito larvae disappeared completely by that time. Our re- 
sults strongly support the widespread knowledge of the high volatility and low persistence of essential oils in the environment (see Isman 2006).

Mortality in the experiment with floating OLE was evident irrespective of the volume of the container where larvae were released. This means that the establishment of a thin film on the surface of the water medium can be lethal to the mosquito larvae in this water medium in a relatively short time $(20 \mathrm{~h})$. Even if we consider that OLE is only partially suspended in the water medium (a portion of it may move down and mix heterogeneously), mosquito larvae need to surface to breathe air and several processes may be responsible for their death (resumed in Corbet et al. 2000). First, larvae cannot breathe due to tracheal flooding by oil, because they cannot keep their position at the water surface due to disruption of the physical forces that allow them to float. Secondly, they avoid reaching the surface due to chemosensory responses. Direct toxicity, due to the volatile fraction of the compound, may represent a latter cause. Independent of the mechanism, applying road drains or other tiny water bodies with appropriate OLE amounts (e. g. ratio $0.1 \mathrm{~mL}: 50 \mathrm{~cm}^{2}$ ) can be extremely effective and with no regard to the exact volume of the container as long as its surface is properly covered with the oil.

In a short term, dissolved OLE can be lethal to gilled vertebrates like Gambusia sp. and tadpoles at concentrations (ppm lower than 500) which tiger mosquito larvae can easily withstand (see Figs. 1, 2). To our knowledge, this is the first evidence for such a result on non-target groups such as amphibians and, except for the information from Zhu et al. 2008 on minnows, the first on other fish species.

Among the compounds present in OLE, alphaPinene and Citronellol, for instance, are known to act as direct defences against herbivores and pathogens in plants. In addition, the role of terpenoids in affecting community and ecosystem properties is well documented in the literature (see Langenheim 1994). More concretely, OLE is known for its general phytotoxic (Batish et al., 2006) and herbicidal properties (Singh et al. 2005). Hence, both low persistence and short-term toxicity against aquatic vertebrates must be taken into account when PMD is used in the environment in spite of EPA and the BPD assessments, which are, in our opinion, based upon confounding interpretations of different results in the litera- ture (i.e. Isman 2000).

Our results support previous findings on the effectiveness of water-mixed OLE in eliminating the larvae of tiger mosquito both at medium and high concentrations and short times. In the medium term (one week), OLE loses its larvicidal properties. As mentioned above, concentrations of water-mixed OLE, which are non lethal to tiger mosquito larvae, are, in contrast, lethal in the short term (less than $35 \mathrm{~min}$ ) to gilled vertebrates like mosquitofish and frog tadpoles. OLE is extremely efficient as a mosquito larvicide when released directly over the surface of containers resulting in a potential larvicide to be used (without mixing it) in a variety of man-made mosquito breeding containers.

In conclusion, OLE appears as a useful compound to be used against the tiger mosquito larvae especially in mosquito breeding sites (e. g. road drains), which are isolated from more native ecosystems. In contrast, in habitats where non-target organisms such as fish or amphibians are present, the use of OLE is not recommended because of the potential effects it may have on native non-target species. Hence, prior to consider a priori any botanical-based compound as environmental harmless (see Dharmagadda et al. 2005), we strongly encourage precise assessment of both medium-term persistence and effects on non-target organisms.

\section{Acknowledgements}

This study was undertaken during a monitoring of the tiger mosquito breeding sites in the Girona province (Catalonia) promoted by the "Servei de Control de Mosquits". We thank Maria Pujalta of the Collserola pharmacy for practical advice on the emulsions and DICANA S.L., for providing the OLE for the experiments and its chromatographic analysis. Special thanks go to Cati Peña and Joan Escartín for providing logistic facilities. Mikel Becerro, Julio C. López-Doval, Rohan Arthur, Isabel Muñoz, and Anna Sans kindly revised the manuscript text and provided many helpful comments.

\section{References}

Abramides G, Roiz D, Guitart R, Quintana S, Guerrero I \& Giménez N. 2011. Effectiveness of a multiple in- 
tervention strategy for the control of the tiger mosquito (Aedes albopictus) in Spain. Transactions of the Royal Society of Tropical Medicine and Hygiene 105: 281-288.

Amer A \& Mehlhorn H. 2006. Larvicidal effects of various essential oils against Aedes, Anopheles, and Culex larvae (Diptera, Culicidae). Parasitology Research 99: 466-472.

Aranda C, Eritja R \& Roiz D. 2006. First record and establishment of the mosquito Aedes albopictus in Spain. Medical and Veterinary Entomology 20: 150152.

Barasa SS, Ndiege IO, Lwande W \& Hassanali A. 2002. Repellent activities of stereoisomers of p-Menthane3,8-diols against Anopheles gambiae (Diptera: Culicidae). Journal of Medical Entomology 39 (5): 736741.

Barnard DR \& Xue R-D. 2004. Laboratory evaluation of mosquito repellents against Aedes albopictus, Culex nigripalpus, and Ochlerotatus triseriatus (Diptera: Culicidae). Journal of Medical Entomology 41 (4): 726-730.

Batish DR, Harminder P, Singh HP, Setiaa N, Kaura S \& Kohlia RK. 2006. Chemical Composition and Phytotoxicity of Volatile Essential Oil from Intact and Fallen Leaves of Eucalyptus citriodora. Zeitschrift für Naturforschung 61c: 465-471.

Carroll SP \& Loye J. 2006. PMD, a registered botanical mosquito repellent with deet-like efficacy. Journal of the American Mosquito Control Association 22 (3): 507-514.

Chantraine J-M, Laurent D, Bollivan C, Saavedra G, Ibañez R \& Vilaseca LA. 1998. Insecticidal activity of essential oils on Aedes aegypti larvae. Phytoterapy Research 12: 350-354.

Corbet SA, Tiley C, Moorhouse T, Giam C, Pursglove S, Raby S \& Rich M. 2000. Surface films as mosquito larvicides: partitioning the mode of action. Entomologia Experimentalis et Applicata 94: 295-307.

Dharmagadda VSS, Naik SN, Mittal PK \& Vasudevan P. 2005. Larvicidal activity of Tagetes patula essential oil against three mosquito species. Bioresource Technology 96: 1235-1240.

Eritja R, Escosa R, Lucientes J, Marquès E, Molina R, Roiz D \& Ruiz S. 2005. Worldwide invasion of vector mosquitoes: present European distribution and challenges for Spain. Biological Invasions 7: 87-97.

Hawley WA.1988. The biology of Aedes albopictus. Journal of the American Mosquito Control Association 4: 1-39.

Hribar LJ, Vlach LJ, Demay DJ, James SS, Fahey JS \& Fussel EM. 2004. Mosquito larvae (Culicidae) and other Diptera associated with containers, storm drains, and sewage treatment plants in the Florida Keys, Monroe County, Florida. Florida Entomologist 87 (2): 199-203.

Idris, HS, Lawal SB \& Balarabe BM. 2008. Larvicidal potentials of leaf and bark extracts of Eucalyptus camaldulensis (Schlect) and Eucalyptus citriodora (Hook) on Culex quinquefasciatus (Say) larvae. Entomological Research 38: 243-249.
Isman MB. 2000. Plant essential oils for pest and disease management. Crop Protection 19: 603-608.

Isman MB. 2006. Botanical insecticides, deterrents, and repellents in modern agriculture and an increasingly regulated world. Annual Review of Entomology 51: 45-66.

Kolpin D, Furlon GE, Meyer M, Thurman EM \& Zaugg S. 2002. Pharmaceuticals, hormones, and other organic wastewater contaminants in U.S. streams, 1999-2000: a national reconnaissance. Available from http://digitalcommons.unl.edu/usgsstaffpub/68/

Langenheim JH. 1994. Higher plant terpenoids, a phytocentric overview of their ecological roles. Journal of Chemical Ecology 20(6): 1223-1280.

Lounibos LP. 2002. Invasions by insect vectors of human disease. Annual Review of Entomology 47: 233-266.

Lucia A, Licastro S, Zerba E \& Masuh H. 2008. Yield, chemical composition, and bioactivity of essential oils from 12 species of Eucalyptus on Aedes aegypti larvae. Entomologia Experimentalis et Applicata 129: 107-114.

Mithöfer A \& Boland W. 2012. Plant defence against herbivores: chemical aspects. Annual Review of Plant Biology 63: 431-450.

Monzon RB, Alvior JP, Luczon LLC, Morales AS \& Mutuc FES. 1994. Larvicidal potential of five Philippine plants against Aedes aegypti (Linneus) and Culex quinquefasciatus (Say). Southeast Asian Journal of Tropical Medicine and Public Health 25(4): 755-759.

Mpuhlu B, 2007. Synthesis of p-menthane-3,8-diol. Available from http://dspace.nmmu.ac.za:8080/jspui/ bitstream/10948/570/1/Master\%20B\%20Muphlu.pdf

Paupy C, Delatte H, Bagny L, Corbel V \& Fontenille D. 2009. Aedes albopictus, an arbovirus vector: From the darkness to the light. Microbes and Infection 11: 1177-1185.

Pereira WE \& Hostettler FD. 1993. Non point source contamination of the Mississippi river and its tributaries by herbicides. Environmental Science \& Technology 27: 1542-1552.

Reiter P. 1998. Aedes albopictus and the world trade in used tyres, 1988-95: the shape of things to come? Journal of the American Mosquito Control Association 14: 83-94.

Rivera-Cancel G, Bocioaga D \& Hay AG. 2007. Bacterial degradation of N,N-Diethyl-m-toluamide (DEET): cloning and heterologous expression of DEET hydrolase. Applied and Environmental Microbiology 73(9): 3105-3108.

Singh HP, Batish DR, Setia N \& Kohli RK. 2005. Herbicidal activity of volatile oils from Eucalyptus citriodora against Parthenium hysterophorus. Annals of Applied Biology 146: 89-94.

Singh RK, Dhiman RC \& Mittal PK. 2007. Studies on mosquito larvicidal properties of Eucalyptus citriodora Hook (Family-Myrtaceae). Journal of Communicable Diseases 39(4): 233-236.

Xue R-D, Barnard DR \& Ali A. 2001. Laboratory and field evaluation of insect repellents as larvicides against the mosquitoes Aedes albopictus and Anopheles albimanus. Medical and Veterinary Entomology 15: 
374-380

Yates MG. 1979. The biology of the tree-hole breeding mosquito Aedes geniculatus (Olivier) (Diptera: Culicidae) in Southern England. Bulletin of Entomological Research 69: 611-628.
Zhu J, Zeng X, O'Neal M, Schultz G, Tucker B, Coats J, Bartholomay L \& Xue R-D. 2008. Mosquito larvicidal activity of botanical-based mosquito repellents. Journal of the American Mosquito Control Association 2: 146-149. 


\section{Erratum-Corrigendum Volumen 37 (2015)}

\section{Corrigendum}

Escartin S \& Mariani S. 2014. Evaluating the toxicity of oil of lemon eucalyptus, Corymbia citriodora (Hook.), against larvae of the Asian tiger mosquito and non-target fish and larval amphibians. Anales de Biología 36: 97-105.

Published on-line: 26 May 2015

The crude extract of the leaves and roots of the lemon eucalyptus Corymbia citriodora often contains a variety of compounds. These are shown in Table 1 of the article. Citronellal is often present at high concentrations (>50\%). If p-Menthane-3.8-diol (PMD) is present in crude C. citriodora oil, it represents only trace amounts (see Barasa et al. 2002). PMD can also be synthesised from Citronellal. PMD represents approximately $65 \%$ of the insect repellent concentrate, Citriodiol ${ }^{\circledR}$ (EPA Reg. No. 84878-3). This refined form of C. citriodora oil is generically known in the USA as oil of lemon eucalyptus or OLE.

In our article we evaluate the toxicity of the unrefined C. citriodora oil, and use the acronym OLE throughout the text to refer to this compound. We, the authors, would like to clarify that the term OLE, as used in our article, refers exclusively to the mix of compounds in Table 1, which does not contain PMD, and should not be confused with the "oil of lemon eucalyptus" or "OLE" as used by the US EPA or Center for Disease Control and Prevention (CDC). Consequently, any misleading conflation between the term OLE (as used in our manuscript) and "oil of lemon eucalyptus" or "OLE" as used by some authorities to describe Citriodiol ${ }^{\circledR}$ or the like is erroneous.

In order to remove any potential misinterpretation, this erratum clarifies that the term OLE used in the article to abbreviate the oil of lemon eucalyptus $C$. citriodora, has no relationship with Citriodiol ${ }^{\circledR}$ and does not contain PMD. All references to OLE in the article should now be substituted with the acronym LEO (lemon eucalyptus oil). Hence the compound shown in Table 1 that was used for the toxicity assays in the present article refers to LEO, and not OLE, PMD, or Citriodiol ${ }^{\circledR}$.

Furthermore, and to avoid any further misunderstanding, we include the following corrigenda: The citation of the article of Carrol and Loye, 2006 on page 98, second column should be ignored.

The sentence on page 98, second column: "The essential oil of lemon eucalyptus is better known as OLE in the USA and as Citriodiol, both in the USA and Europe. The oil is also well known for its larvicidal properties (Singh et al. 2007, Idris et al. 2008, Zhu et al. 2008), although it is still unclear if PMD Citronellal or other components either in the oil or the water-soluble fractions of the extract is primarily responsible for this larvicidal property (see Zhu et al. 2008)." should be replaced with: "The essential lemon eucalyptus oil is known for its larvicidal properties (Singh et al. 2007, Idris et al. 2008, Zhu et al. 2008), although it is still unclear if Citronellal or other components, either in the oil or the water-soluble fractions of the extract, is primarily responsible for this larvicidal property (see Zhu et al. 2008)."

The sentence at the start of the Discussion section on page 102: "The effectiveness of the oil extract by the lemon eucalyptus $C$. citriodora as a mosquito repellent has long been recognized (summarized in Carroll \& Loye 2006) and there is a clear global commercial interest for PMD, both natural and synthetic (Barnard \& Xue 2004). In Catalonia (Spain), for instance, where the presence of the tiger mosquito represents a relatively recent issue (the first recording dating back to 2004 (Aranda et al. 2006)), PMD and Citriodiol are already being proposed as mosquito repellents in a city hall's web page." should be expunged, since our study did not consider the effects of PMD or Citriodiol ${ }^{\circledR}$. Consequently, the two references in this sentence should be ignored.

The following sentence on page 102: "The larvicidal properties of any derivate of OLE..." should be substituted with: "The larvicidal properties of the LEO components..."

The sentence on page 103, at the end of the first column: "Hence, both low persistence and short-term 
toxicity against aquatic vertebrates must be taken into account when PMD is used in the environment in spite of EPA and the BPD assessments, which are, in our opinion, based upon confounding interpretations of different results in the literature (i.e. Isman 2000)." should be replaced with: "Hence, when compounds contained in C. citriodora oil are used in the environment, it is important to factor in both their low persistence as well as their short-term toxicity against aquatic vertebrates."

Santi Escartin \& Simone Mariani

Nuestras excusas por estos errores

We apologize for these errors

Juan José Presa \& Francisco Collantes

Editores

Editors 